\title{
GÉNERO Y ANTOLOGÍAS: LA REVISIÓN DEL CANON EN LA ERA DE LA CIBERCULTURA Y EL PROYECTO CIEN DE CIEN (2015-2016) ${ }^{1}$
}

\author{
GENDER AND ANTHOLOGIES: RECASTING THE CANON \\ IN THE ERA OF CYBERCULTURE AND IN THE PROJECT \\ CIEN DE CIEN (2015-2016)
}

\author{
Raquel FERNÁNDEZ MENÉNDEZ \\ Universidad de Oviedo \\ fmraquel@uniovi.es
}

\begin{abstract}
Resumen: En este artículo se estudia la importancia que Internet ha tenido en los últimos años en la recepción de las poetas españolas contemporáneas. Para ello, se recurre tanto a la teoría literaria feminista y al ciberfeminismo como a algunas de las contribuciones clave en el estudio de los procesos de canonicidad, específicamente, a la sociología de Pierre Bourdieu y a la teoría de los polisistemas de Itamar Even-Zohar. Desde este marco teórico, se analiza la antología virtual Cien de cien de Elena Medel, una selección que permite repensar las relaciones entre autoridad, cánones y cibercultura en el siglo XXI.
\end{abstract}

Palabras clave: Literatura española. Cibercultura. Estudios de género. Canon. Elena Medel.

\begin{abstract}
This article aims to study the importance that the Internet has had in the reception of Spanish women poets in the last few years. For that purpose, feminist literary criticism and cyberfeminism will be used, as well as some of the key contributors to the study of canon, particularly Pierre Bourdieu's sociology and Itamar Even-Zohar's theory of polysystems. With this theoretical framework, attention will be paid to the digital anthology Cien de cien by Elena Medel, which enables us to rethink the relationship between authority, literary canons and cyberculture in the $21^{\text {st }}$ Century.
\end{abstract}

Keywords: Spanish Literature. Ciberculture. Gender Studies. Canon. Elena Medel.

\footnotetext{
${ }^{1}$ Este trabajo ha contado con la financiación del Programa Severo Ochoa de ayudas predoctorales para la investigación y la docencia del Gobierno del Principado de Asturias (referencia PA-17-PF-BP16126) y se enmarca en el Proyecto "Extraños cosmopolitas: Mundos alternativos en la escritura contemporánea" (RTI2018-097186-B-I00) del Programa Estatal de I+D+i “Retos investigación”. Asimismo, debo agradecer a Elena Medel la información y los materiales que me facilitó sobre el proyecto Cien de cien.
} 


\section{CANONICIDAD Y CIBERCULTURA: UNA PERSPECTIVA DE GÉNERO}

Las dinámicas de producción y distribución de la literatura originadas con la extensión de Internet a comienzos del siglo XXI han ejercido una innegable influencia en el conjunto del sistema cultural que, bien entrado el nuevo milenio, constituye aún un reto para los estudios literarios, cuyas aportaciones teóricas han estado sujetas a la rápida transformación que este medio continúa experimentando (Sánchez Mesa, 2004: 12-13). En este sentido, uno de los desafíos a la hora de considerar la impronta de la red en el campo literario, entendido, en los términos de Pierre Bourdieu, como una "red de relaciones objetivas (de dominación o subordinación, de complementaridad o antagonismo, etc.) entre posiciones" (1995: 342), es la actual convivencia entre la pantalla y el papel (Delany y Landow, 2006: 47). Por un lado, algunos de los rasgos constitutivos de la textualidad virtual, como la desmaterialización, la admisión libre y la dispersión de los textos (Delany y Landow, 2006: 52-59), parecen haber fomentado la aparición de nuevas formas de leer y escribir que exigen un cambio en nuestro modo de entender la literatura. Por otro, la existencia de dos posturas antagónicas ante este fenómeno - la de las instituciones tradicionales que han visto en Internet el fin de todo conocimiento auténtico (Sánchez Mesa, 2004: 15), y la de quienes, por el contrario, valoran sus posibilidades para la difusión de las obras que han ocupado una posición marginal en el canon (Benéitez Andrés, 2013: 208-209; Rodríguez-Gaona, 2019: 23-24; Jauralde Pou, 2019: 301) —, no solo pone de manifiesto que la creación en línea está ya completamente integrada en el campo literario, sino que, como ya se ha sugerido (Sánchez Mesa, 2004: 18; Vilariño Picos y Abuín González, 2006: 15), las viejas tensiones entre el privilegio de ciertos textos y la voluntad de desvelar la naturaleza política de los procesos de selección de las obras, tarea compartida por la crítica cultural y la teoría literaria feminista, han de ser asuntos nucleares en un debate, que, sin embargo, no parece haber recibido la necesaria atención en España según nos aproximamos a la tercera década del siglo XXI.

A finales de los años setenta del siglo XX, las dos corrientes teóricas de mayor calado en la crítica feminista occidental, las desarrolladas, respectivamente, desde las tradiciones de pensamiento angloamericana y francesa (Moi, 1988: 11), señalaron la exclusión de las escritoras de los cánones como un problema central en sus investigaciones. En Estados Unidos, los trabajos de Elaine Showalter, Sandra Gilbert y Susan Gubar o Annette Kolodny se ocuparon no solo de recuperar y analizar las peculiaridades de las obras escritas por mujeres, ausentes de las historias de la literatura y de los planes de estudio de las universidades, sino también de plantear un acercamiento pluralista a los textos que negaba el carácter definitivo de cualquier interpretación. Se trataba de "una confrontación con los cánones y juicios existentes" (Showalter, 1999: 77) que pretendía dotar de las herramientas críticas adecuadas al lector/a, y que rechazaba la normalidad con la que la 
exégesis masculina había condenado el punto de vista femenino en la lectura de las obras (Showalter, 1971: 856).

Al mismo tiempo, en Francia, los trabajos de Hélène Cixous y Luce Irigaray exploraban la necesidad de que las escritoras adoptaran un estilo fluido y dinámico, que opondría resistencia a los tópicos de lo femenino dictados por la cultura patriarcal, y que cuestionaría los espacios de prestigio de los que, reiteradamente, se han excluido los nombres de mujer (Cixous, 2015: 37; Irigaray, 2009: 84). Una écriture féminine o parler femme desde la diferencia que se basaría en la reapropiación y en la reescritura con el objetivo de disolver los pares opuestos sobre los que se ha asentado el espacio social (hombre/mujer, cultura/naturaleza, público/privado), y que han limitado históricamente el acceso de las mujeres al conocimiento (Cixous, 2015: 37). A su vez, en sus ensayos sobre Clarice Lispector (Cixous, 1995: 157-198) o Marina Tsvetáieva (Cixous, 1990: 1119), Hélène Cixous incidía en la importancia de la recuperación de una literatura específicamente femenina que demandaba ser interpretada desde una perspectiva disidente con la crítica dominante, tarea compartida con las especialistas angloamericanas, que, muy pronto, comprendieron la particularidad de las obras de autoría femenina con respecto a la tradición hegemónica (Gilbert y Gubar, 1998: 11-12; Showalter, 1982: 11).

Estas aportaciones resultaron fundamentales a la hora de cuestionar nociones como las de canon y autoridad, y, por ello, suponen todavía hoy una referencia obligada para valorar si la aparente carencia de jerarquías definitoria de la World Wide Web permite una verdadera transformación en la producción y en la recepción de los textos escritos por mujeres, históricamente rechazados en el sistema tradicional. Desde esta óptica, no se debe pasar por alto que, en las postrimerías del siglo XX, la extensión de Internet permitió a las investigadoras feministas adoptar una sensibilidad positiva hacia la tecnología, que comenzó a ser explorada por sus posibilidades para un cambio de paradigma en las relaciones sociales de género (Wajcman, 2006: 50). El "Manifiesto Cyborg" de Donna Haraway, publicado originalmente en 1984, fue pionero en exponer la "simbiosis" entre humanos y máquinas al definir "un organismo cibernético, un híbrido de máquina y organismo, una criatura de realidad social y también de ficción" (1991: 253). La transgresión de las fronteras implícita en el cyborg (entre máquina y organismo, reproducción e imaginación, espacio público y privado y cuerpo y mente, entre otras), así como su voluntad antiesencialista, influiría en posteriores concepciones del ciberespacio como el universo postgénero planteado por Haraway. Continuando sus planteamientos, Sadie Plant defendería que la pérdida de atributos físicos que opera en el ciberespacio supone una oportunidad para la liberación de los tradicionales binarismos de género que han servido para dividir a hombres y mujeres de acuerdo con pares opuestos, de modo que permite "acceder a recursos que antes estaban limitados a aquellos que tenían el aspecto, el acento, la raza y el sexo adecuados" (1998: 52). En consecuencia, en sus comienzos, Internet parecía abrir oportunidades inéditas para la creación artística de las 
mujeres, y, por tanto, también nuevas oportunidades para los lectores/as, que tendrían a su alcance obras que anteriormente eran de difícil acceso.

Con todo, los trabajos de Rosi Braidotti (2004: 108-109) y Judy Wajcman (2006: 156157) matizaron pronto el excesivo entusiasmo en torno a las posibilidades postgénero de Internet al señalar la interdependencia entre tecnología y sociedad. Se comenzaba a cuestionar la inclinación utópica de ensayos como el de Plant, que habían anunciado ambiciosos cambios de paradigma en la construcción de las identidades en la era digital. En realidad, es bien sabido que existe una marcada brecha de género en el acceso a los dispositivos informáticos, y que la red propone imágenes y representaciones del binomio hombre-mujer similares a las del universo analógico, lo que supone en ambos casos un obstáculo para la transformación de las estructuras sociales de dominación (Braidotti, 2004: 122-124). Así, Braidotti proponía la "incardinación”, entendida como la redefinición de los cuerpos en los nuevos contextos digitales, como estrategia de liberación que permitiera desencializar a la mujer como "el otro objetivado del patriarcado" (2004: 127) en el marco tecnológico. La feminidad devendría "una opción a una serie de posturas disponibles, a un conjunto de costumbres ricas en historia y a relaciones sociales de poder, pero ya no fijadas ni compulsivas" (2004: 127). Asumido este enfoque, la integración de Internet en el contexto de las relaciones sociales permitiría detectar mejor cómo las tecnologías pueden llegar a producir cambios en estas (Wajcman, 2006: 157-161) y, consecuentemente, valorar con una mayor precisión el alcance en el campo cultural de las obras firmadas por mujeres en la red.

Por este motivo, este caudal teórico que, sin renunciar a las posibilidades de Internet para la reivindicación feminista, asume su lugar en el entramado social, resulta un excelente punto de partida para retomar y actualizar el que, como se ha señalado, ha sido uno de los ejes de la teoría literaria feminista desde los años setenta: el estudio de las relaciones de las escritoras con las instituciones garantes del prestigio (universidades, crítica y público, entre otros) que dictan la pervivencia de determinados nombres en las historias de la literatura. En este sentido, hay que tener en cuenta que el interés de los estudios literarios por la cibercultura y el desarrollo del pensamiento ciberfeminista a lo largo de la década de los años noventa transcurre de forma paralela a la polémica en torno al canon en las universidades estadounidenses, reflejada en una intensa pugna sobre el lugar que los clásicos deben ocupar en la era digital (Pozuelo Yvancos, 2000: 17). Al peso que la crítica feminista y cultural habían ejercido al desvelar los procesos ideológicos que subyacen en la elaboración del canon, se sumaba ahora la aparente supresión de la autoridad sobre la que se ha insistido al hablar de Internet (Poster, 2004: 182; Delany y Landow, 2006: 57; Žižek, 2006: 207), que contribuiría a la entrada en el sistema de cualquier texto sin someterlo previamente a la intervención de los distintos agentes del mercado editorial.

Sin embargo, los temores expuestos por Harold Bloom en el controvertido ensayo El canon occidental (1994) sobre una supuesta destrucción del canon de la mano de la que él mismo denominó Escuela del Resentimiento (que incluía, entre otras corrientes de 
pensamiento, a la crítica feminista) (1995: 11), y las consecuencias que Sven Birkets auguraba para la era electrónica (el empobrecimiento del lenguaje, la supresión de todo sentido cronológico de la historia, y el final del individualismo que está en la base de la lectura) (1999: 169-173) parecen estar aún lejos de producirse. Si bien se han originado profundos cambios en las prácticas de lectura, como se comprobará en las siguientes páginas, la interdependencia entre la pantalla y el papel ha sometido a la literatura en red a los mismos procesos de canonización mantenidos a lo largo de la historia, ya que la interpretación y la circulación de los textos sigue estando en gran medida condicionada por el funcionamiento de la institución académica y de las diversas subinstituciones que, como la prensa cultural o los grupos de lectura, determinan la interpretación y la pervivencia de las obras al paso del tiempo (Kermode, 1998: 91-93).

Tal y como han anotado ya algunos de los últimos trabajos centrados en analizar la transformación que los textos publicados en Internet han producido en el mercado editorial español (Rodríguez-Gaona, 2019; 12-13; Bagué Quílez, 2018: 333; Martín Gijón, 2011: 357), la convivencia entre las nuevas tecnologías, que permiten un menor filtrado de los textos que se publican, y el libro, que continúa siendo fundamental como garantía del reconocimiento de las obras (Kerckhove, 1999: 146), organiza el campo literario en dos sistemas (virtual y analógico) en pugna por la acumulación de lo que Pierre Bourdieu denominó “capital simbólico" (1995: 327-328). Esta noción, que aglutina a aquellos campos, como el cultural o el literario, en los que el valor de los objetos artísticos depende de los gustos de los grupos privilegiados por las relaciones de poder vigentes en el espacio social (Bourdieu, 2015: 129-130), ha resultado sumamente operativa para comprender los procesos que dictan qué obras literarias son prestigiadas en cada etapa (Pozuelo Yvancos, 2000: 105-120).

La desigual distribución del "capital simbólico" condiciona la posición ocupada en el campo literario por dominantes y dominados, y dota a los segundos de las herramientas necesarias para desarrollar estrategias con el fin de mejorar su posición (Bourdieu, 1995: 342-345; Moore, 2008: 103-105). Tal y como ya ha sido puesto de manifiesto desde el ámbito de los estudios literarios (Pozuelo Yvancos, 2000: 105-106; Sullà, 1998: 29), esta teoría, muy iluminadora para el análisis de los procesos de canonización de los textos, enlaza con la noción de "polisistema", inicialmente propuesta por Itamar Even-Zohar, que, de forma similar a la sociología de Bourdieu, sitúa su foco de atención en las relaciones que producen los cambios en el reconocimiento de las obras. En su indagación en las pautas que dirigen el funcionamiento de la literatura, la teoría polisistémica incide en la coexistencia simultánea de numerosas redes de relaciones tanto en la periferia como en el centro del campo literario, cuya posición está determinada por normas que son extensivas al resto de la sociedad (Iglesias Santos, 1999: 18-19). Tanto los trabajos de Bourdieu como el punto de vista polisistémico permiten atribuir a los procesos de canonicidad una naturaleza dinámica, ya que se caracterizan por el desplazamiento de nombres y obras desde la periferia hacia uno de los centros del sistema (Even-Zohar, 1979: 295; Sheffy, 1999: 511). Esta óptica contribuye no solo a comprender mejor la 
influencia que la literatura distribuida inicialmente en Internet ha tenido posteriormente a través de la publicación de libros de gran tirada en reputadas editoriales, fenómeno que ha sido frecuente en los últimos años con el surgimiento de la poesía en las redes (Corral Cañas, 2015; Rodríguez-Gaona, 2019), sino, además, a valorar hasta qué punto ciertas comunidades virtuales, destinadas a la recuperación de las obras escritas por mujeres, han ejercido una notable influencia en una industria editorial que ha comenzado a prestar atención a textos anteriormente apartados de los grandes catálogos.

Como ha estudiado Remedios Zafra, en los últimos años, en España se han llevado a cabo varios proyectos en red (entre otros, Helvéticas o La Tribu) ${ }^{2}$ destinados no solo a recuperar la obra de las escritoras ausente de las antologías e historias de la literatura, sino también a fomentar determinadas "estrategias de contralectura" (2017:110) próximas al acercamiento pluralista de los textos planteado por la crítica feminista anglosajona y francófona en los años setenta y ochenta del siglo pasado. Así, mientras que Helvéticas ofrece talleres de escritura, La Tribu — portal renombrado en 2020 como La tribu. Una casa propia - proponía textos alternativos a los seleccionados por un mercado editorial con marcado sesgo de género. En este sentido, estas comunidades no solo retoman la tarea de presentar una tradición alternativa, tal como ocurría en los primeros trabajos críticos feministas, sino que, a partir de la red, permiten que muchas obras que carecían de una buena distribución lleguen a un público mucho más amplio y alcancen una visibilidad que podrá influir en un necesario cambio de posición en el campo literario. De ahí que, para Remedios Zafra, Internet haya contribuido en gran medida a una clara desarticulación y resignificación de las "tradiciones literarias y relaciones de poder, atravesando las prácticas y posiciones de lectura y escritura de las mujeres en la actualidad" (2017: 109); a través de la "incardinación" (Braidotti, 2004: 111) de los sujetos en la red como una estrategia de oposición a los tópicos esencialistas que aún pesan sobre la lectura y la autoría femeninas en el siglo XXI, portales como La Tribu han conseguido, ciertamente, que un importante número de textos, cuyos planteamientos se alejan de los universales hegemónicos, recuperen un espacio central en la esfera cultural que anteriormente les estaba vedado.

En el marco de los procesos de canonicidad que definen el sistema y que permiten que, en momentos señalados, los grupos periféricos alcancen el centro (Sheffy, 1999: 134), estas comunidades lectoras dotarían a las obras escritas por mujeres del "capital simbólico" necesario para, posteriormente, influir sobre los mecanismos más tradicionales de selección de los textos (Martín Gijón, 2011: 358; Rodríguez-Gaona, 2019: 57). De hecho, dada la convivencia entre la red y el papel, resulta innegable que estas comunidades han ejercido una enorme influencia en las decisiones de las editoriales,

\footnotetext{
${ }^{2}$ Helvéticas. Escuela de escritura ve la luz en el año 2009 como un espacio virtual que pretende establecer vínculos entre mujeres interesadas tanto en el aprendizaje de la escritura a través de talleres, como en la participación en clubes de lectura en línea. Por su parte, La Tribu, coordinado por Carmen G. de la Cueva entre 2014 y 2019, se centra en la selección y recopilación de obras firmadas por autoras contemporáneas, y presta una especial atención al ensayo feminista a través de la publicación de diarios, artículos y fragmentos de memorias de escritoras e investigadoras de diversas generaciones.
} 
que han visto en las escritoras contemporáneas una oportunidad de éxito de mercado. Así, resulta especialmente pertinente abordar el fenómeno a través de un género tradicionalmente minoritario como la poesía, ya que la obra de algunas poetas españolas del siglo XX, situadas en los márgenes del canon ${ }^{3}$, no solo ha comenzado a ser reproducida en las redes tras años en el silencio, sino que, paralelamente, ha sido reeditada para su distribución en librerías. Además, en los últimos años, la publicación en papel de las llamadas "antologías de género" (Balcells, 2006), destinadas a recuperar la producción olvidada de un gran número de escritoras contemporáneas - como ocurre, por ejemplo, con las selecciones de Lanseros y Merino (2016) o Gorría (2018) respectivamente-, así como de la preparación de documentales para televisión, como Las Sinsombrero de Tania Batlló para RTVE o Se dice poeta de Sofía Castañón (Navarrete Navarrete, 2019), han dotado a estas poetas de una "visibilidad" que, como ha estudiado Nathalie Heinich (2012: 46), es en sí misma una forma de "capital simbólico" imprescindible para el reconocimiento del autor/a o artista.

Sin embargo, es justamente esta óptica, que tiene en cuenta el importante papel desempeñado por la visibilidad en el campo literario actual, la que invita a valorar hasta qué punto estos proyectos virtuales, que tratan de responder a las sesgadas dinámicas de exclusión de las escritoras de los cánones, tienen una verdadera incidencia en la transformación "de las categorías de percepción y de valoración legítimas" (Bourdieu, 1995: 237). La pregunta ha de dirigirse entonces a si, desde la cibercultura, pueden producirse cambios tanto en los criterios de selección (Navas Ocaña, 2020: 342) como en los sujetos autorizados para dictar lecturas que contribuyan a que determinados textos puedan pasar a formar parte del "capital cultural objetivado" (Bourdieu, 1995: 267-268) en el que se incluyen las obras canonizadas, ya que si bien existe un interés económico derivado de la publicación de una literatura que ya ha alcanzado un gran éxito en las redes, este fenómeno no tiene por qué venir acompañado de un reconocimiento con el paso del tiempo. En este sentido, Bourdieu insiste en que “el capital 'económico' sólo puede proporcionar los beneficios específicos ofrecidos por el campo $-\mathrm{y}$ al mismo tiempo los beneficios 'económicos' que a menudo estos reportarán a largo plazo - si se reconvierte en capital simbólico" (1995: 224). Como ha sido señalado anteriormente, en el campo literario la acumulación de este "capital simbólico" depende, en gran medida, de la posterior inclusión en los cánones que organizan la historia literaria, por lo que, si

\footnotetext{
${ }^{3}$ En los últimos años ha habido varias editoriales que han recuperado la obra de poetas como Ernestina de Champourcin, Josefina de la Torre, Carmen Conde o Ángela Figuera Aymerich a través de la publicación de antologías y de la reedición de muchos de sus libros descatalogados. Por un lado, pequeños sellos de larga tradición en la edición de obras escritas por mujeres como Torremozas han mantenido una intensa actividad, y nuevos proyectos como La Bella Varsovia o Sabina editorial han tratado de continuar su legado. Por otro, editoriales en cuyos catálogos no aparecían hasta la fecha demasiados nombres de mujer han comenzado a prestar atención a sus obras. El mejor ejemplo de este nuevo interés es el caso de Gloria Fuertes, ya que, a raíz del centenario de su nacimiento en el año 2017, sellos que cuentan con una gran distribución, como Blackie Books o Nórdica, se interesaron por su figura, lo que, a su vez, motivó que la poeta ocupara las portadas de títulos de la prensa cultural española de la notoriedad de El Cultural, Babelia o ABC Cultural.
} 
bien no se debe despreciar la influencia de estas páginas web, cuyo impacto ha dotado a las escritoras de una mayor visibilidad, sus propuestas están en interdependencia con las dinámicas de la publicación en papel que garantizarían una preservación de los textos a largo plazo.

Comprender el desplazamiento de estos textos que comienzan a ser ampliamente reconocidos en el ámbito de la cibercultura para ser posteriormente aceptados desde los grandes grupos editoriales que determinan su posterior institucionalización no solo resulta fundamental para historiar los cambios operados en los cánones en España, sino también para valorar el papel de las "estrategias de contralectura" (Zafra, 2017: 110) en la redefinición de las reglas que organizan el funcionamiento del campo en un momento dado. Así, en el marco digital, sigue resultando pertinente recurrir a la noción de autoridad aún cuando se trata de plantear lecturas alternativas a la tradición hegemónica, ya que no se trata tanto de elucubrar en torno a la posible entrada de los textos reproducidos en red en los programas de estudio del futuro, requisito que ha definido históricamente a las obras canonizadas (Bou, 2010: 176), sino de evaluar si realmente existe una modificación en las pautas que determinan los mecanismos de selección dada la convivencia entre los soportes digitales y analógicos.

En este contexto, un caso que requiere ser analizado es el de Cien de cien, una antología virtual de poetas nacidas entre 1892 (Pilar de Valderrama) y 1966 (Luisa Castro) impulsada por la editora y poeta Elena Medel y publicada en la plataforma de microblogging Tumblr entre los meses de junio de 2015 y marzo de 2016. Por un lado, el interés de esta muestra reside en la actualización de los códigos que han definido a las antologías poéticas contemporáneas (la reproducción de una selección de poemas junto con una serie de paratextos como las notas biográficas, los retratos del autor/a o las poéticas, que dan cohesión al conjunto), libros estrechamente vinculados con la inclusión de ciertos nombres en el canon poético, para adaptarlos al nuevo soporte digital que, a su vez, tiene en cuenta a escritoras anteriormente ausentes de estas nóminas. Por otro lado, el proyecto permite abordar la estrecha relación entre la red y el papel, debido tanto al reconocimiento de Elena Medel fuera de las pantallas ${ }^{4}$, como a la voluntad de publicar una antología en La Bella Varsovia, editorial dirigida por la propia antóloga, que complementaría la labor desempeñada en Internet.

\footnotetext{
${ }^{4}$ Además de su labor como editora en La Bella Varsovia, la obra poética de Elena Medel ha sido reconocida con premios como el Fundación Princesa de Girona de Artes y Letras (2016) o el Loewe a la Creación Joven (2014), y con la inclusión en antologías como El canon abierto. Última poesía en español (19701985) de Remedios Sánchez García y Anthony L. Geist o Ilimitada voz: antología de poetas 1940-2002 de José María Balcells. Como novelista, ha publicado Las maravillas (2020) en la editorial Anagrama, obra merecedora del Premio Francisco Umbral al libro del año 2020.
} 


\section{CIEN DE CIEN: ANTOLOGÍAS, AUTORIDAD Y "ESTRATEGIAS DE CONTRALECTURA"}

La fecha de la primera entrada publicada en el portal Cien de cien (27 de junio de 2015) enlaza inevitablemente el proyecto con una de las polémicas que con más virulencia se ha manifestado en el panorama poético español de los últimos años, la desencadenada por las palabras con las que, pocos días antes, el editor Jesús García Sánchez, conocido como Chus Visor, negaba en una entrevista a Nuria Azancot la existencia en España de una poesía escrita por mujeres de la calidad de la masculina:

Lo siento, pero creo que la poesía femenina en España no está a la altura de la otra, de la masculina, digamos, aunque tampoco es cosa de diferenciar. Desde luego, si vas a coger a las poetas desde el 98 para acá, es decir, todo el siglo XX, no ves ninguna gran poeta, ninguna, comparable a lo que suponen en la novela Ana María Matute o Martín Gaite. No hay una poeta importante ni en el 98, ni en el 27, ni en los 50, ni hoy. Hay muchas que están bien, como Elena Medel, pero no se la puede considerar, por una Medel hay cinco hombres equivalentes (Azancot, 2015).

A pesar de que la antología se desvinculó pronto de esta anécdota ${ }^{5}$ para convertirse en un proyecto mucho más amplio de recuperación de las obras escritas por poetas españolas contemporáneas, merece la pena tener en cuenta estos prejuicios, ya que, además de sintetizar meridianamente algunos de los tópicos que tradicionalmente han servido para negar el acceso de las mujeres a la escritura - la inconsistencia, la excepcionalidad y la anormalidad de aquellas que escriben (Russ, 1983: 39-86) - , fueron pronto rechazados en Internet con el lanzamiento de Cien de cien y del manifiesto "Justicia poética ya", firmado en la plataforma Change.org por más de 400 profesionales de la industria del libro. Estas respuestas revelan las actuales tensiones entre los dos medios a los que me vengo refiriendo: por un lado, las palabras de Chus Visor ponen de manifiesto hasta qué punto los agentes de mayor prestigio del campo continúan exponiendo bien entrado el siglo XXI un marcado sesgo de género que impide un posible cambio en el privilegio que, en un determinado período, ciertos textos adquieren de acuerdo con las dinámicas de los procesos de canonización; por otro, el enorme potencial de Internet, como espacio "donde la visibilidad es fácilmente aumentada, multiplicada y extendida" (Zafra, 2013: 23), permite la recuperación de aquellas obras no aceptadas por la crítica hegemónica $\mathrm{y}$, consecuentemente, un abierto rechazo a los prejuicios dominantes.

Entre el 27 de junio de 2015 y el 25 de marzo de 2016, en el portal se publicó una entrada diaria encabezada por el nombre de cada poeta y el título del poema reproducido.

\footnotetext{
${ }^{5}$ En una entrevista a Inés Martín Rodrigo, Elena Medel indicó la relación del inicio del proyecto con las opiniones vertidas por el editor en junio de 2015: "Me llamó la atención la ausencia absoluta de mujeres y, por mi cuenta, poco a poco, empecé a investigar de una manera muy precaria. Empecé a pensar en la idea de hacer una antología y cuando se publicó esta entrevista me pareció que lo mejor era contestar con poemas de autoras de esa franja” (Martín Rodrigo, 2018).
} 
Tras él, se incluían una breve nota bibliográfica, varios enlaces a distintos recursos en red, que permitían navegar por la página y enlazar a las escritoras entre sí (artículos científicos, entrevistas, reseñas e incluso vídeos), y, por último, una fotografía y las etiquetas o hashtags ("años50", "años60", "exilio"). De este modo, los volúmenes en papel, de alcance anteriormente muy limitado (gran parte de los libros que se citan en la página web no se han vuelto a reeditar desde la fecha de publicación del original), e ineficaces a la hora de dotar de visibilidad a las autoras, son sustituidos por el hipertexto ${ }^{6}$, que no solo garantiza una distribución más eficaz, sino que propone una lectura no lineal, basada en el desplazamiento entre los textos y otros documentos secundarios a voluntad del lector/a (Castany Prado, 2019: 256). De la misma manera, en la pestaña de la página denominada "Contacto", la antóloga aceptaba el envío de propuestas por correo electrónico y hacía posible una interacción entre obra y lector/a que produciría una “desjerarquización" (Castany Prado, 2019: 258) entre autora/antóloga y público. Los rasgos de la textualidad en red singularizan así a Cien de cien con respecto al resto de antologías poéticas publicadas en papel y permiten hablar de una modificación de los modos tradicionales de producción y circulación de la poesía, lo que proporcionaría un primer cauce para la gestación de una comunidad lectora no representada en las elecciones de los grandes grupos editoriales.

Sin embargo, existían claras muestras de la autoridad de la antóloga en el sitio web que impiden aceptar la total pérdida de jerarquías en el ciberespacio, hecho que, a su vez, tiene importantes repercusiones a la hora de valorar la posibilidad de un cambio en el estatuto de las creadoras en la era digital. No se debe pasar por alto que la preparación de antologías se ha apoyado históricamente en quien compila, que no es "un mero reflector del pasado, sino quien expresa o practica una idea de la literariedad, fijando géneros, destacando modelos, afectando el presente del lector y, sobre todo, orientándole hacia un futuro" (Guillén, 1985: 417). En este sentido, es necesario valorar hasta qué punto el gran alcance del proyecto, que se ha visto ampliado en diversas actividades fuera de las redes ${ }^{7}$, y al que la prensa ha prestado abundante atención (Remacha, 2016; Azancot, 2016), depende del prestigio de Elena Medel como escritora y antóloga, reconocida incluso en la entrevista a Chus Visor como un caso excepcional entre sus contemporáneas. Desde esta óptica, considerar el portal Cien de cien como una antología implica poner en evidencia la aparente horizontalidad que caracteriza a la escritura y a las comunidades lectoras en red. Así las cosas, la oportunidad de proponer "estrategias de contralectura" (Zafra, 2017: 110) quedaría limitada por la influencia en el ciberespacio de las tendencias

\footnotetext{
${ }^{6}$ Tal y como recuerdan Vilariño Picos y Abuín González, "el hipertexto es un conjunto formado por textos y 'documentos' (las llamadas lexias o scriptons) no jerarquizados unidos entre ellos por enlaces (links o liens) que el lector puede activar y que permiten un acceso rápido a cada uno de los elementos constitutivos de ese conjunto" (2006: 19).

7 Tras la preparación del portal web, Elena Medel ha llevado a cabo diversos proyectos derivados de él. Entre otros, destacan sus colaboraciones con el Diario de Sevilla, donde, bajo el título "Claro del bosque", publicó, a lo largo del año 2015, una serie semanal dedicada a ocho escritoras andaluzas, y la organización de recitales como "Cien de cien. Poetas españolas del siglo XX (y XXI)", celebrado en el marco del festival Ellas crean en el Auditorio de Conde Duque (Madrid) el 29 de marzo de 2016.
} 
ya vigentes en el campo literario, lo que condicionaría en gran medida el potencial de Internet para promover cambios en las dinámicas de formación del canon.

La inclusión en el blog de los paratextos que caracterizan a las antologías en papel (citas, prólogos, poéticas y elementos iconográficos) y que, tal y como defiende José Francisco Ruiz Casanova, contribuyen "en alto grado a perfilar la autoría del antólogo y a construir el libro como tal" (Ruiz Casanova, 2007: 163), son fundamentales a la hora de comprender hasta qué punto la autoridad de quien elige determinados textos, con la voluntad de producir un cambio en la posición que ocupan en el campo, se mantiene en las plataformas digitales. Estos paralelismos entre el aparato paratextual de la antología virtual y el de las selecciones en papel no han de ser pasados por alto, ya que el conjunto adquiere así una coherencia (Genette, 2001: 7-8) que está determinada por la "reescritura o reelaboración por parte de un lector, de textos ya existentes mediante su inserción en conjuntos nuevos" (Guillén, 1985: 413). De este modo, la preferencia por ciertos poemas y retratos de las escritoras sobre otros, la redacción de las notas biográficas, y la necesidad de justificar que la muestra sea "caprichosa, injusta y subjetiva" (retórica propia de las antologías en papel) obligan a encontrar en la aparente horizontalidad de la red rastros de una jerarquía que es determinante para la fijación de estas obras en el canon poético del siglo XXI.

Un ejemplo paradigmático de cómo la imitación de la estructura propia de la antología en Cien de cien da coherencia al conjunto a través de la selección y de los paratextos que la apoyan es sin duda la reproducción, en la primera entrada del portal, del poema "El cielo" de Ángela Figuera Aymerich (Bilbao, 1902-Madrid, 1984). La recuperación en el sitio web del texto originalmente publicado en Belleza cruel (1958), una de las más significativas muestras del compromiso social de la poeta contra la dictadura de Franco, no supone un mero ejercicio revisionista, sino que, en un contexto de agitado debate en torno a la sistemática ausencia de autoras en los cánones, se convierte en una interesante reescritura. En él, la poeta vasca se dirigía con mordaz ironía a quienes, ante la cruda realidad de posguerra, optaban por escribir una poesía acrítica que obviaba las precarias condiciones de vida de gran parte de la población, y reivindicaba una literatura disidente con aquellos textos aceptados por los órganos de prestigio. En el marco de la respuesta digital a la polémica suscitada por Chus Visor en torno a la inferior calidad de la poesía escrita por las poetas españolas contemporáneas, Elena Medel actualiza el contenido del poema para reivindicar otros puntos de vista a la hora de escoger qué obras son reconocidas en los cánones del siglo XXI. Así, en su difusión en las redes, el texto verá ampliado su significado original, proceso en el que los siguientes versos juegan un importante papel:

Yo, así, lo cantaría con toda unción. Palabra.

Con versos bien rimados, para dormir tranquila

sabiendo que tenía mi puesto asegurado

en las Antologías del Arte más conspicuo.

Pero es casi imposible. Pues yo no veo el cielo (Figuera Aymerich, 1986: 221). 
En el poema, el "cielo" cubierto es metáfora de la imposibilidad de obviar la dura realidad en la España bajo el franquismo, sin embargo, recuperado en la antología virtual, la misma imagen apunta al difícil acceso de las autoras a las mismas "Antologías del Arte más conspicuo" (Figuera Aymerich, 1986: 221), debido en gran medida al tratamiento de temas que no se corresponden con los universales masculinos y que han servido para leer desde la extrañeza las obras escritas por mujeres. En este sentido, el amplio alcance del poema propiciado por Internet, unido a la intervención antológica de quien asume una perspectiva en desacuerdo con los poderes hegemónicos del campo, permite no solo recuperar una tradición que ha sido ignorada desde los órganos de reconocimiento, sino, además, proponer una interpretación de los textos en disenso con las prácticas de lectura que han determinado dicha exclusión. Por ello, como defenderé a continuación, Cien de cien no solo visibiliza, sino que, además, propone, a través de las distintas entradas del portal, un cuestionamiento del relato dominante sobre la poesía española del siglo XX de notable influencia en las políticas editoriales de los últimos años.

\section{LA LECTURA COMO REVISIÓN: EL PAPEL DE CIEN DE CIEN}

Entre los proyectos surgidos fuera de las redes a partir de Cien de cien es preciso destacar ahora el prólogo que Elena Medel preparó en 2016 para la reedición en Torremozas de Oratorio de San Bernardino (1950) de Alfonsa de la Torre ${ }^{8}$. Por un lado, porque este trabajo resulta indisociable de la tarea de revisión y recuperación llevada a cabo en la página web, y pone de manifiesto el estrecho diálogo entre la pantalla y el papel en el campo literario actual; por otro, porque se vierten en este breve ensayo ideas sobre la interpretación de las obras escritas por mujeres que, como se comprobará, podrían funcionar a modo de poética de la antología virtual.

El interés de Elena Medel por el poemario de Alfonsa de la Torre había quedado anotado previamente en una entrada publicada en Cien de cien el 16 de enero de 2016 en la que la antóloga lo situaba al frente de un listado de "Diez libros escritos por poetas españolas (y publicados en la segunda mitad del siglo XX)". En la recopilación se consideraban, además, Poemas del suburbio (1954) de Gloria Fuertes, Belleza cruel (1958) de Ángela Figuera Aymerich, Poemas de Cherry Lane (1968) de Julia Uceda, Marta \& María (1976) de María Victoria Atencia, Resurrección de la memoria (1978) de Paloma Palao, De una niña de provincias que se vino a vivir en un Chagall (1981) de

\footnotetext{
${ }^{8}$ Alfonsa de la Torre (Cuéllar, 1918-1993) desarrolló su trayectoria poética principalmente en la década de los cuarenta, momento en el que reside en Madrid y se inserta en los círculos poéticos de la capital. Entre sus obras, cabe destacar Égloga (1943), Oda a la Reina del Irán (1948), Oratorio de San Bernardino (1950) y Plazuela de las obediencias (1969). Para un estudio del poemario que nos ocupa puede acudirse a los trabajos de María Payeras Grau (2009: 137-154; 2018). Importa notar que Oratorio de San Bernardino mereció el Premio Nacional de Poesía en 1951, pero solo se había reeditado en 2011 como parte de la Obra poética (Torre, 2011), un volumen financiado por el Ayuntamiento de Cuéllar, que, dada su limitada distribución, resulta hoy prácticamente imposible de encontrar.
} 
Blanca Andreu, Baleas e baleas (Ballenas) (1992) de Luisa Castro, Pantalones blancos de franela (1994) de Inmaculada Mengíbar, y, por último, Poesía (1996), la edición de la obra poética de Lucía Sánchez Saornil editada póstumamente.

Al situar este título escasamente conocido como antecedente de los poemarios publicados durante la democracia, se proponía una nueva aproximación a la historia de la poesía española contemporánea que partía de la relectura tanto de la obra de Alfonsa de la Torre como de la de sus contemporáneas Carmen Conde, Concha Zardoya, Elena Martín Vivaldi, María Beneyto, Pilar Paz Pasamar, María Elvira Lacaci, Julia Uceda, Aurora de Albornoz, Cristina Lacasa, Elena Andrés, Pino Betancor o Concha de Marco, a quienes se dedicó secciones en el sitio web ${ }^{9}$. Sin embargo, será en la presentación de la trayectoria de Alfonsa de la Torre en el prólogo a la edición en papel de Oratorio de San Bernardino, donde, al comentar la reseña que Gerardo Diego dedica a este libro, se defienda la importancia de asumir una perspectiva revisionista no ya únicamente sobre los textos seleccionados, sino, además, con respecto a las prácticas de lectura que han determinado el estatuto marginal de ciertas obras.

El crítico defendía que, al aproximarse a Oratorio de San Bernardino, era necesario llevar a cabo "una lectura y relectura atenta hasta dar tiempo a empaparse de todas sus esencias y de penetrar del brazo de sus motivos de pasión, ternura, gozo y violencia hasta el hondón de todos sus símbolos y conceptos" (1951: s. p.), sin embargo, Elena Medel apuntaba que, aunque Diego "se esfuerza por elogiar — y lo consigue con sinceridad — la obra de Alfonsa de la Torre, muchas de las referencias de Oratorio de San Bernardino se le escapan" (Medel, 2020 [2016]: 20), entre ellas, el importante paganismo de la autora y la carga feminista del libro - señalada también más recientemente por especialistas como María Payeras Grau (2018) - Como resultado, Medel consideraba que "en cierto modo, interpretamos los textos ajenos según los criterios propios. Así obra Gerardo Diego, que encuentra en la poesía de Alfonsa de la Torre aquello que ha querido buscar" (Medel, 2020 [2016]: 19), una afirmación que cobra todo su sentido si se recupera ahora el potencial que Remedios Zafra (2017: 109) concede a Internet como un medio para desvelar las relaciones de poder en las tradiciones literarias, puesto que los presupuestos de Elena Medel vertidos aquí alcanzan su verdadero potencial a través de las prácticas interpretativas alternativas propuestas desde la red a través de Cien de cien.

En este sentido, ha de tenerse en cuenta que - a diferencia de la mayor parte de los portales destinados a publicar poesía en red, que, por lo general, se centran en la publicación de obras inéditas-, Cien de cien tenía como objetivo principal la recuperación de textos olvidados en el ámbito académico y editorial, de modo que la propuesta exigía de una búsqueda en los archivos y de una confrontación con las posiciones críticas ante los textos. Según quedaba indicado al pie de las entradas correspondientes, "Elegía a los niños del bosque de Bolonia" de Alfonsa de la Torre, "La

\footnotetext{
${ }^{9}$ Para una aproximación a estas autoras puede consultarse el trabajo de María Payeras Grau (2009), donde se aportan importantes datos sobre las trayectorias poéticas de las creadoras que publican sus obras en los años cuarenta y cincuenta del siglo XX.
} 
meta" de Susana March, "Tranquilizaos..." de Trina Mercader o "Fijación del instante" de María Alfaro se habían tomado de Poesía femenina española (1939-1950) (1967) de Carmen Conde ${ }^{10}$, una antología de género pionera que permitía publicar en el portal poemas que ni siquiera habían aparecido en formato libro. En consecuencia, no solo se recuperaban ciertos textos con el objetivo de garantizar una mejor distribución, sino también aproximaciones previas a los mismos que, como la de Conde, prestaban una especial atención a la perspectiva de género.

Además, en Cien de cien, las poetas consideradas por Carmen Conde en su antología compartían espacio con aquellas que se habían dado a conocer en los ochenta y los noventa como Fanny Rubio, Concha García, Ángeles Mora, Almudena Guzmán, Paloma Palao, Esther Zarraluki, Inmaculada Mengíbar, Esperanza López Parada, Amalia Bautista, Ada Salas o Luisa Castro. De este modo, el criterio no cronológico - las entradas se publicaban de acuerdo con la preferencia de la antóloga - proponía una aproximación dinámica a la historia de la poesía española contemporánea en la que, a través del hipervínculo, era posible establecer lazos temáticos y estéticos entre el conjunto de nombres seleccionados con independencia de la fecha original de publicación de los poemas.

En este sentido, la propuesta de Elena Medel se posicionaba también al margen de algunas de las antologías de género que, como Las diosas blancas (1985) de Ramón Buenaventura, contribuyeron al reconocimiento de las poetas nacidas en los años cincuenta y sesenta como Blanca Andreu, Almudena Guzmán o Luisa Castro. En esta selección se optaba por aislar a estas autoras de las de las décadas centrales del siglo, puesto que, en opinión del antólogo, hasta la fecha, "había una notable diferencia de calidad a favor de los hombres" (Buenaventura, 1985 [1986]: 21) que solo se habría solventado en la etapa de la democracia. Con el apoyo de propuestas críticas previas como la de Carmen Conde — pasadas por alto en el libro de Ramón Buenaventura - y a través de un proceso de revisión de textos como los de Ángela Figuera Aymerich y Alfonsa de la Torre que, tal y como lo definió Adrienne Rich, constituía un "acto de mirar hacia atrás, de mirar con ojos nuevos, de entrar en un nuevo texto desde una dirección crítica nueva"11 (1972: 18), Elena Medel demostraba que no existían razones para este prejuicio.

Sin embargo, antes de cerrar este apartado, cabe preguntarse de nuevo si, además de un incentivo para que se publiquen ediciones de textos olvidados, un proyecto como Cien de cien puede convertirse en una propuesta historiográfica susceptible de ser asimilada en el ámbito académico y editorial. En este sentido, no cabe duda de que el reconocimiento previo de Elena Medel como escritora y editora determina que su posición de lectura frente a una tradición no hegemónica sea legítima para los medios de prestigio $y$, en consecuencia, pueda promover cambios a largo plazo en la historia de la

\footnotetext{
${ }^{10}$ Elena Medel emplea la reedición de la antología Poesía femenina española viviente (1954) de Carmen Conde, publicada en fechas próximas a la publicación de libros como los de Alfonsa de la Torre, Gloria Fuertes o Ángela Figuera Aymerich.

${ }^{11}$ La traducción es mía.
} 
literatura. Si bien esta circunstancia no suprime las posibilidades de ejercer una resistencia más general a la crítica dominante a través de la red, obliga, necesariamente, a comprender los muchos matices de la realidad "polisistémica" del campo literario actual, en el que las tensiones entre autoría y género continúan encerrando interesantes retos teóricos. Al recuperar, en el marco de la cibercultura, un debate como el de las complejas relaciones de las obras escritas por mujeres con los cánones, la red se presenta como un espacio ambivalente, donde, si bien se facilita que determinados grupos dominados en el campo literario adopten "estrategias de contralectura" (Zafra, 2017: 110), su eficacia estará en gran medida ligada a la autoridad de quien desarrolla esta tarea, y a la posterior influencia de la muestra en la publicación en papel.

De hecho, es necesario destacar que la iniciativa de Elena Medel ha tenido una notable repercusión en la publicación en papel de un gran número de antologías de género por parte de diversas editoriales que han comenzado a emplear un punto de vista similar a la hora de recuperar la posguerra - una etapa que, como se pudo comprobar, se privilegiaba en Cien de cien - como un momento de una importancia capital para comprender la poesía escrita por mujeres en el siglo XXI. A este respecto, llama especialmente la atención que, incluso Visor, dirigida por quien fuera protagonista de la polémica en torno a la calidad de la escritura hecha por mujeres, imprimiera, tan solo un año después de la citada entrevista, la selección Poesía soy yo, preparada por Raquel Lanseros y Ana Merino, cuyo arco cronológico, que incluía poetas nacidas entre 1886 y 1960, era muy similar al propuesto por Elena Medel en su antología virtual. Por otra parte, a pesar de que el propio editor defendió que la antología se encontraba en elaboración tiempo antes del estallido de la polémica mencionada ${ }^{12}$, resulta inevitable considerar la publicación de este libro tanto como un intento de limpiar la imagen del sello en un momento de profundos cambios en la recepción de la literatura escrita por mujeres, como de aprovechar el rendimiento de mercado despertado por el aumento de la "visibilidad" (Heinich, 2012) de estas autoras en el ciberespacio.

Por todo ello, aunque queda demostrada la incidencia en la modificación de las políticas editoriales por parte de propuestas de "contralectura" llevadas a cabo desde la red, la acumulación del "capital simbólico" de las obras seleccionadas a largo plazo requiere de un cambio mucho más profundo en las estructuras de poder vigentes en el espacio social, una transformación que solo se verá reflejada con la inclusión de un mayor número de poesía escrita por mujeres en los programas de estudio y las historias de la literatura en el futuro. En este sentido, aunque, tal y como afirma Remedios Zafra (2017: 109), Internet posibilita alterar las posiciones de lectura que determinan la formación del canon, no se deben eludir la importancia de la labor de la antóloga en una red aparentemente desjerarquizada y el prestigio de Elena Medel como una voz autorizada

\footnotetext{
12 Tal y como se recoge en la noticia de prensa publicada en el diario El País, el propio Chus Visor defendió la autonomía de la aparición de la antología con respecto de la polémica al señalar que "comenzamos a trabajar en esta antología hace dos años. Muchos pensarán que la sacamos a raíz de la polémica creada, pero no es así” (Ruiz Mantilla, 2016).
} 
para dilucidar el valor de los textos literarios, lo que, necesariamente, obliga a evitar una mirada excesivamente positiva al potencial de la red para la transformación de las relaciones entre género y canonicidad.

\section{CONCLUSIONES}

En las páginas previas se ha defendido la necesidad de asumir un punto de vista interdisciplinar cuando se trata de estudiar la repercusión que Internet ha tenido en los últimos años en la publicación de la poesía escrita por mujeres. Por un lado, la propuesta de Elena Medel asume una voluntad de revisión de los cánones como la que motivó a la crítica feminista en sus primeras indagaciones en los años sesenta y setenta del siglo XX. Por otro, para analizar la influencia de Cien de cien en el campo literario actual resulta imprescindible llevar a cabo un estudio de los procesos de canonicidad que tenga en cuenta tanto la teoría sociológica de Pierre Bourdieu como la teoría de los polisistemas de Itamar Even-Zohar, en tanto que estos enfoques contribuyen a comprender por qué la cibercultura depende del funcionamiento del sistema editorial, académico y crítico para llegar a motivar verdaderos cambios en las prácticas de lectura e interpretación de las obras literarias, lo que obliga, necesariamente, a matizar la influencia de estos proyectos cuando no cuentan con el respaldo de una figura reconocida previamente.

Con todo, la "incardinación" en el ciberespacio de un "sujeto situado" (Braidotti, 2004: 111) que lee, selecciona y propone obras para su fijación en el canon, a partir de la reivindicación de textos que adoptan puntos de vista históricamente no aceptados, pone de manifiesto que el estudio de la recepción de la literatura escrita por mujeres en la España contemporánea está sometida a la incidencia de los nuevos soportes digitales. El nuevo contexto virtual en el que se inserta la antología Cien de cien permite articular nuevas preguntas ante nociones de tan largo recorrido como las de antología, historia de la literatura y canonicidad, perspectiva desde la que el centro del debate parece apuntar directamente a cómo las lecturas, que, de la mano de antólogos/as e historiadores/as, modelan la historia de la literatura, pueden estar siendo transformadas desde espacios donde la regulación y las jerarquías propias de la institución parecen suspenderse.

\section{REFERENCIAS BIBLIOGRÁFICAS}

AzANCOT, N (2015). "Chus Visor: 'Dicen que los novelistas son vanidosos ipero hay cada poeta!"”. El Cultural, 26 de junio. Disponible en línea: https://elcultural.com/chus-visor-dicen-que-los-novelistas-son-vanidosos-perohay-cada-poeta [30/12/2020].

(2016). "Poesía, femenino singular". El Cultural, 24 de junio. Disponible en línea: https://elcultural.com/Poesia-femenino-singular [30/12/2020]. 
BAguÉ QuíleZ, L. (2018). "Atrapados en la red: los mundos virtuales en la poesía española reciente". Kamchatka. Revista de Análisis Cultural 11, 331-349. Disponible en línea: https://ojs.uv.es/index.php/kamchatka/article/view/11424 [08/11/2020].

BAlcells, J. M. (2006). "Del género de las antologías 'de género"”. Arbor. Ciencia, Pensamiento, Cultura 182.721, 635-649. Disponible en línea: http://arbor.revistas.csic.es/index.php/arbor/article/view/58 [06/10/2020].

BENEITEZ ANDRÉS, R. (2013). "Para una estética de lo variable: poesía y crítica en red". En Malos tiempos para la épica. Última poesía española (2001-2012). L. Bagué Quílez y Alberto Santamaría (eds.), 207-220. Madrid: Visor Libros.

BIRKETS, S. (1999). Elegía a Gutenberg: el futuro de la lectura en la era electrónica, D. Manzanares (trad.). Madrid: Alianza Editorial.

Bloom, H. (1995). El canon occidental, D. Alou (trad.). Barcelona: Anagrama.

Bou, E. (2010). "Bloqueo Digital: perversidad en las autobiografías público-privadas". En Nuevos hispanismos interdisciplinarios y transatlánticos, J. Ortega (dir.), 161178. Frankfurt-Madrid: Iberoamericana.

Bourdieu, P. (1995). Las reglas del arte. Génesis y estructura del campo literario, T. Kauf (trad.). Barcelona: Anagrama.

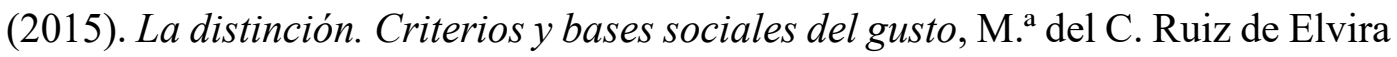
(trad.). Madrid: Taurus.

BRAIDOTTI, R. (2004). "El ciberfeminismo con una diferencia”. En Feminismo, diferencia sexual y subjetividad nómade, Amalia Fischer Pfeiffer (ed.), 107-130. Barcelona: Gedisa.

Buenaventura, R. (1986 [1985]). Las diosas blancas. Antología de la joven poesía española escrita por mujeres. Madrid: Hiperión.

CAStany Prado, B. (2019). "Ciberliteratura y cibercultura en el ámbito hispánico". Tropelías. Revista de Teoría de la Literatura y Literatura Comparada 31, 237283. Disponible en línea: https://papiro.unizar.es/ojs/index.php/tropelias/article/view/3074 [20/01/2021].

Cixous, H. (1990). "Difficult Joys". En The Body and the Text. Hélène Cixous, Reading and Teaching, H. Wilcox, K. McWatters, A. Thompson \& L. R. Williams (eds.), 5-30. Hertfordshire: Harvester Wheatsheat.

(1995). La risa de la medusa. Ensayos sobre la escritura, A. M. ${ }^{a}$ Moix (trad.). Barcelona: Anthropos.

(2015). La llegada a la escritura, I. Agoff (trad.). Buenos Aires-Madrid: Amorrortu.

Corral CAÑAs, C. (2015). Nuevos ámbitos en la creación de arte verbal. Poesía española contemporánea en la Red. Salamanca: Universidad de Salamanca.

DELANY, P. Y LANDOW, G. P. (2006). "Gestionando la palabra digital: el texto en la época de la reproducción electrónica”. En Teoría del hipertexto. La literatura en la era electrónica, Ma Teresa Vilariño Picos y Anxo Abuín González (eds.), 37-74. Madrid: Arco/Libros. 
DiegO, G. (1951). "Alfonsa de la Torre". $A B C, 26$ de abril. Disponible en línea: https://www.abc.es/archivo/periodicos/abc-madrid-19510426-3.html [04/04/2021].

Even-Zohar, I. (1979). "Polysystem Theory". Poetics Today 1.1-2, 287-310.

Figuera AyMerich, Á. (1986). Obras completas. Madrid: Hiperión.

Genette, G. (2001). Umbrales, S. Lage (trad.). México D. F.: Siglo XXI Editores.

GILBERT, S. M. Y GUBAR, S. (1998). La loca del desván. La escritora y la imaginación literaria del siglo XIX, C. Martínez Gimeno (trad.). Madrid: Cátedra.

GorríA, A. (2018). Antología de poetas españolas. De la generación del 27 al siglo XV. Barcelona: Alba.

GuILlÉN, C. (1985). Entre lo uno y lo diverso. Introducción a la literatura comparada. Barcelona: Crítica.

HaRAWAy, D. (1991). Ciencia, cyborgs y mujeres. La reinvención de la naturaleza, M. Talens (trad.). Madrid: Cátedra.

HeInich, N. (2012). De la visibilitée. Excellence et singularité en régime médiatique. Paris: Gallimard.

Iglesias SANTOS, M. (1999). "La teoría de los polisistemas como desafío a los estudios literarios”. En Teoría de los Polisistemas, M. Iglesias Santos (ed.), 9-22. Madrid: Arco / Libros.

Irigaray, L. (2009). Ese sexo que no es uno, R. Sánchez Cedillo (trad.). Madrid: Akal. Jauralde Pou, P. (2019). "La poesía en la era de Internet". Signa. Revista de la Asociación Española de Semiótica 28, 299-305. Disponible en línea: http://revistas.uned.es/index.php/signa/article/view/25053/19895 [15/1/2021].

KERCKHOVE, D. de (1999). Inteligencias en conexión: hacia una sociedad de la web. Barcelona: Gedisa.

KERMODE, F. (1998). "El control institucional de la interpretación”. En El canon literario, Enric Sullà (ed.), 91-112. Madrid: Arco / Libros.

Kolodny, A. (1980). "Dancing through the Minefield: Some Observations on the Theory, Practice and Politics of a Feminist Literary Criticism". Feminist Studies $6.1,1-25$.

Lanseros, R. \& Merino, A. (2016). Poesía soy yo. Poetas en español del siglo XX (18861960). Madrid: Visor Libros.

MARTín GiJón, M. (2011). "La blogosfera en el campo literario español. ¿Espacios en conflicto o vanguardia asimilada?”. En Literatura e internet. Nuevos textos, nuevos lectores, Salvador Montesa (ed.), 355-366. Málaga: AEDILE.

MARTín Rodrigo, I. (2018). "Elena Medel: 'En las editoriales de poesía con prestigio las mujeres no existen"”. $A B C, 4$ de marzo. Disponible en línea: https://www.abc.es/ cultura/libros/abci-elena-medel-editoriales-poesia-prestigio-mujeres-no-existen201803040128_noticia.html [28/01/2021].

Medel, E. (2020 [2016]). "Alfonsa de la Torre: mujer con bosque". Introducción a Oratorio de San Bernardino, Alfonsa de la Torre, 7-21. Madrid: Torremozas. 
MoI, T. (1988). Teoría literaria feminista, A. Bárcena (trad.). Madrid: Cátedra.

Moore, R. (2008). “Capital”. En Bourdieu. Key Concepts, Michael Grenfell (ed.), 101117. Durham: Acumen.

Navarrete Navarrete, M. T. (2019). “Se dice poeta: Poesía española, mujer y nuevas tecnologías". Signa. Revista de la Asociación Española de Semiótica 28, 245-269. En línea: http://revistas.uned.es/index.php/signa/article/view/25048/19876 [15/01/2021].

NAVAS OCAÑA, I. (2020). "Las escritoras en el canon de la literatura digital en español". Studia Neophilologica 92.3, 337-360.

PAyeras Grau, M. (2009). Espejos de palabra. La voz secreta de la mujer en la poesía española de posguerra (1939-1959). Madrid: UNED.

(2018). "Claves para la lectura de Oratorio de San Bernardino, de Alfonsa de la Torre". Signa. Revista de la Asociación Española de Semiótica 27, 857-882. En línea: $\quad$ http://revistas.uned.es/index.php/signa/article/view/18660/17878 [03/04/2021].

Plant, S. (1998). Ceros +unos, E. Urios (trad.). Barcelona: Destino.

Poster, M. (2004). "La ciberdemocracia: Internet y la esfera pública”. En Literatura y cibercultura, Domingo Sánchez Mesa (ed.), 177-197. Madrid: Arco / Libros.

Pozuelo Yvancos, J. M. (2000). "Teoría del canon”. En Teoría del canon y literatura española, José María Pozuelo Yvancos y Rosa María Aradra Sánchez (eds.), 15140. Madrid: Cátedra.

REMACHA, B. (2016). “Cien de cien: al rescate de las poetas silenciadas". Eldiario.es, 28 de marzo. En línea: https://www.eldiario.es/cultura/libros/poesia/Cien-cienviaje-tiempo-poetas_0_499400340.html [07/01/2021].

RICH, A. (1972). "When When We Dead Awaken: Writing as Re-vision". College English 34.1, 18-30.

RodríGUEZ-GAONA, M. (2019). La lira de las masas. Internet y la crisis de la ciudad letrada. Una aproximación a la poesía de los nativos digitales. Madrid: Páginas de Espuma.

Ruiz Casanova, J. F. (2007). Anthologos. Poética de la antología poética. Madrid: Cátedra.

Ruiz MantiLla, J. (2016). "Una antología salda cuentas con el olvido a las poetas en castellano". El País, 20 de junio. Disponible en línea: https://elpais.com/cultura/2016/06/15/actualidad/1465988788_175490.html [20/01/2021].

Russ, J. (1983). How to Suppress Women's Writing. Austin: University of Texas Press.

SÁNCHEZ MESA, D. (2004). "Los vigilantes de la metamorfosis. El reto de los estudios literarios ante las nuevas formas y medios de comunicación digital”. En Literatura y cibercultura, Domingo Sánchez Mesa (ed.), 11-34. Madrid: Arco / Libros. 
SHEFFY, R. (1999). "Estrategias de canonización: la idea de novela y de campo literario en la cultura alemana del s. XVIII". En Teoría de los Polisistemas, Montserrat Iglesias Santos (ed.), 125-146. Madrid: Arco / Libros.

Showalter, E. (1971). "Women and Literary Curriculum”. College English 32.8, 855862.

(1982 [1977]). A Literature of their Own. From Charlotte Brontë to Doris Lessing. London: Virago.

(1999). "La crítica feminista en el desierto". En Otramente: lectura y escritura feministas, Marina Fe (coord.), 75-111. Ciudad de México: Fondo de Cultura Económica, 1999.

SullÀ, E. (1998). "El debate sobre el canon literario". En El canon literario, Enric Sullà (ed.), 11-34. Madrid: Arco / Libros.

Torre, A. DE (2011). Obra poética. Madrid/Cuéllar: EILA/Ayuntamiento de Cuéllar.

Vilariño PiCos, M. ${ }^{a}$ T. y Abuín GonZÁlez, A. (2006). "Historias multiformes en el ciberespacio. Literatura e hipertextualidad". En Teoría del hipertexto. La literatura en la era electrónica, M. ${ }^{\mathrm{a}}$ Teresa Vilariño Picos y Anxó Abuín González (eds.), 13-33. Madrid: Arco / Libros.

Wajcman, J. (2006). El tecnofeminismo, M. Martínez Solimán (trad.). Madrid: Cátedra.

ZAFRA, R. (2013). (h)adas. Mujeres que crean, programan, prosumen, teclean. Madrid: Páginas de Espuma.

(2017). "Mujeres que están leyendo”. En ¿Cómo leemos en la sociedad digital? Lectores, booktubers y prosumidores, Francisco Cruces (coord.), 107-127. Madrid/Barcelona: Fundación Telefónica y Ariel.

ŽIŽEK, S. (2006). Lacrimae rerum: ensayos sobre cine moderno y ciberespacio, R. Vilá Vernis (trad.). Madrid: Debate.

Fecha de recepción: 29/01/2021

Fecha de aceptación: 08/04/2021 